\title{
DISPONIBILIDADE E ASPECTOS JURÍDICOS DA GESTÃO DA ÁGUA DOCE NO BRASIL: UM CAMINHO PARA O ALCANCE DA AGENDA 2030
}

\section{THE AVAILABILITY AND LEGAL ASPECTS OF THE FRESH WATER MANAGEMENT IN BRAZIL: A PATH TO REACH THE 2030 AGENDA}

\author{
Cláudio Barbosa Fontes Filho 1 \\ Ester Dorcas Ferreira dos Anjos 2
}

\section{RESUMO}

A pesquisa busca analisar a disponibilidade e os aspectos da gestão da água doce no Brasil. A Agenda 2030 corresponde ao conjunto de programas, ações e diretrizes que orientarão os trabalhos das Nações Unidas e de seus países membros rumo ao desenvolvimento sustentável. O estudo se justifica pelas alterações na sociedade e no meio ambiente, afetando a relação do homem com a água. A pesquisa pretende verificar se os instrumentos jurídicos de gestão contemplados por nossa legislação atendem aos objetivos traçados pela ONU. Para o desenvolvimento da pesquisa foi utilizado o método indutivo e os procedimentos histórico e bibliográfico.

Palavras-chave: Água, Aspectos jurídicos, Gestão da água, Agenda 2030

\section{ABSTRACT}

This research has as object of analysis the availability and the aspects of water management in Brazil. The 2030 Agenda corresponds the set of programs, actions and policies that will guide the UN work and its member countries towards a sustainable development. This study is justified by the society and environment changes, which affect the relation between human being and water. This research intends to verify if the legal management instruments contemplated by our legislation meet the goals set by the UN. For the development of this research, the inductive method and the historic and bibliographic procedures were used.

Keywords: Water, Legal aspects, Water management, 2030 agenda

\footnotetext{
${ }^{1}$ Mestrando do Programa de Pós-Graduação Stricto Sensu em Ciência Jurídica da Universidade do Vale do Itajaí - UNIVALI. Juiz de Direito em Santa Catarina. E-mail:<cfontesfilho@tjsc.jus.br>

2 Mestre em Ciências Jurídicas pela Universidade do Vale do Itajaí - UNIVALI, Professora de Direito Penal e Processo Penal pela Universidade do Vale do Itajaí. E-mail <ester.anjosbc@gmail.com>
} 


\section{INTRODUÇÃO}

O meio ambiente sofreu, desde a era primitiva, e sofre alterações decorrentes das ações do homem, certo que a utilização dos recursos naturais é necessária à própria subsistência humana. Até pouco tempo, acreditava-se que esses recursos eram inesgotáveis, o que, através dos séculos, acabou por nos legar um conjunto de degradação e poluição.

A partir da Conferência das Nações Unidas sobre Meio Ambiente realizada em Estocolmo,em1972,aspreocupaçõescomomeioambientedeixaramdeserumcaprichopara se tornar uma proposta de proteção da natureza, contextualizada nos dias atuas sob a ótica da sustentabilidade.

Com relação à água o discurso não é diferente. Ambientalistas e técnicos, com justificada preocupação, vêm alertando sobre o risco global da escassez de água doce, e nãosó para as futuras, mas também para as presentes gerações. Em decisão histórica adotada por 193 países, incluindo o Brasil, a Organização das Nações Unidas lançou a Agenda 2030, um contrato social entre os líderes mundiais destinado ao alcance dos 17 Objetivos de DesenvolvimentoSustentável.

A água está entre esses objetivos para os próximos 15 anos, até em razão da crise da água surgida no limiar do século XXI, impondo dificuldades em diversos setores, como economia,saúdeeaodesenvolvimentocomoumtodo,alémdegrandeameaçaàsobrevivência dos seres vivos doplaneta.

O fato de o Brasil ter o privilégio de deter $12 \%$ da água doce de superfície no mundo impõe-lhe maior responsabilidade, a exigir a utilização dos seus instrumentos de gestão, com envolvimento da sociedade, de empresários e de representantes dos grupos de interesses, com vistas a enfrentar os desafios e objetivos traçados pela Agenda 2030.

Estapesquisapartedaseguintehipótese:“‘oBrasil,comprometidocomaAgenda2030, dotadodegrandedisponibilidadedeáguadocedistribuídaporsuasbaciashidrográficas,possui instrumentos jurídicos de gestão hábeis a atingir o objetivo número 6 dos Objetivos do Desenvolvimento Sustentável, que busca 'garantir a disponibilidade de água e sua gestão sustentável e saneamento paratodos'?".

O objeto da presente pesquisa é a análise da disponibilidade e os aspectos jurídicos da gestãodaáguadocenoBrasilcomoumcaminhoparaoalcancedaAgenda2030.SeuObjetivo Geral é investigar os aspectos jurídicos da gestão da água no Brasil, e seus Objetivos Específicos são a análise das propriedades e da importância da água; a compreensão do ciclo hidrológico e da distribuição de água doce no planeta; comentários sobre a escassez da águae 
sobre a necessidade de sua proteção; a conceituação da gestão sustentável da água e, ao final, a verificação do regime jurídico de gestão das águas no Brasil.

Espera-se, com o enfrentamento da pesquisa, acrescentar ao leitor algum conhecimento sobre o tema, sem a finalidade de esgotar o assunto,mesmo porque a abordagem sedá de forma reflexiva, utilizando o procedimento histórico ebibliográfico.

\section{1 Água: suas propriedades e suaimportância}

A água, desde os primórdios da vida no planeta Terra, sempre foi essencial à qualquer forma de vida. Sua história está relacionada ao crescimento populacional e aos diversos usos desse elemento.

Alguns autores, como Veiga, Bianchi e Pompeu, sustentam que a água "é o bem mais preciso do milênio" (VIEGAS, 2005, p. 23), "é o recurso mais importante do mundo" (BIANCHI, apud VIEGAS, 2005, p. 23), ou "ainda elemento natural, descomprometido com qualquer uso ou utilização" (POMPEU, 1999, p. 602).

Barth (1987, p. 1987) a conceitua como um recurso natural, renovável pelos processos físicos do ciclo hidrológico ${ }^{1}$. E assim sendo, a Terra comporta-se como um gigantesco destilador, em que a água, após evaporar-se dos oceanos, dos lagos, dos rios e da superfície terrestre, precipita-se sob a forma de chuva, neve e gelo, corre pela superfície, infiltra-se no subsolo, escoa pelos aquíferos, é absorvida pelas plantas e transpirada pela atmosfera, da qual torna a precipitar-se, e assim sucessivamente.

Em três estados, sólido, líquido e gasoso, a água tem propriedades extraordinárias e é asubstância mais encontrada na natureza, tanto na atmosfera quanto na hidrosfera e na

litosfera.

Denominada solvente universal, justamente porque pode dissolver mais substâncias do quequalqueroutrolíquido,temporessapropriedadecomofundamentalparaavida:nosórgãos vitais do corpo humano, constitui $75 \%$ do cérebro, $86 \%$ dos pulmões, $86 \%$ do fígado, $81 \%$ no sangue, $75 \%$ nos músculos, $75 \%$ no coração e $83 \%$ nos rins. Além disso, a água umidifica os tecidos da boca, dos olhos e do nariz, regula a temperatura corporal, protege os órgãos e os tecidos do corpo, lubrifica as articulações, reduz a sobrecarga nos rins e no fígado através da eliminação de resíduos, ajuda a dissolver minerais e outros nutrientes para deixá-losacessíveis ao corpo, e transporta nutrientes e oxigênio para ascélulas. 
Por esse motivo, conforme enfatizam Casarin e Santos (2011, p. 17), "um ser humano pode sobreviver até cinco semanas sem comer, mas sem água ele não passa de uma semana".

Definida como um composto químico formado de dois átomos de hidrogênio e um de oxigênio (H2O), a água constitui unidade de medida de densidade e seus pontos de solidificação $0^{\circ} \mathrm{C}$ e de ebulição $100^{\circ} \mathrm{C}$ servem como base para a mais utilizada escala termométrica(Celsius).SegundoSilva(2004,p.93-94),aságuasestãoemconstantecirculação, presentes tanto na atmosfera sob a forma de vapor, quanto na superfície do solo sob a forma líquida, ou mesmo no interior do subsolo em lençóisaquíferos.

Por sua singularidade, a água pode ser encontrada em seus três estados, em temperaturas normalmente registradas na Terra, e, frise-se, somente na Terra, pois é o único planeta - ao menos até agora conhecido - que possui as variações de temperatura e pressão atmosférica que permitem a existência desses três estados da água.

Explica Cech (2013, p. 21) que:

[...] aoníveldomar, aáguacongelaaos $32^{\circ} \mathrm{F}\left(0^{\circ} \mathrm{C}\right)$ eferveaos $212^{\circ} \mathrm{F}\left(100^{\circ} \mathrm{C}\right)$.

Entretanto, a 14.000 pés $(4267 \mathrm{~m})$ acima do nível do mar, a temperatura da água precisa chegar apenas a $186^{\circ} \mathrm{F}$ a $\left(86^{\circ} \mathrm{C}\right)$ para ferver. Outra propriedade incomumdaáguaéadequenoestadosólido(gelo)suadensidadeémenordo que no estado líquido, daí ser possível o gelo flutuar. Muitas substâncias líquidas se contraem quando ficam mais frias e a água se comporta damesma forma. No entanto, a água atinge a sua densidade máxima no estado líquido, na temperatura de $39^{\circ} \mathrm{F}\left(4^{\circ} \mathrm{C}\right)$, apenas alguns graus acima do seu ponto de congelamento. Nessa temperatura, a água começa a congelar da superfície para baixo, e então flutua como um sólido (gelo)[...]

Veja-se que se "não tivesse essa propriedade, não teríamos icebergs; os blocos de gelo afundariam e lagos, lagoas, rios e até os oceanos acabariam congelando debaixo para cima" (CECH, 2013, p. 21), e então a vida não existiria como a conhecemos. Essa camada de gelo flutuante "atua como isolante, protegendo a vida existente no estado líquido, abaixo da superfície congelada e permitindo que ela persista". (CECH, 2013, p. 21).

Cech(2013,p.21)aindaapontaoutraespecialpropriedadedaágua,asuaelevadatensão superficial - a medida da tensão da lâmina superficial daágua.

A água tende a se unir em pequenas gotas, criando uma lâmina espessa o suficiente para permitir que insetos e pequenas substâncias mantenham seu peso na superfície da água. Dos líquidos que possuem essa característica em comum, só é superada pelo mercúrio, por sua elevada tensão superficial. Esta propriedade permite que a ação capilar ocorra. Nas plantas, trata-se de processo de deslocamento das gotículas de água das raízes para cima; em 
nossos corpos, o sangue flui através de capilares, minúsculos vasos, devido à propriedade de atração molecular.

Como afirmava Tales de Mileto já no século VI a.C., a água está na base de todas as coisas e é o elemento de sustentação da vida, daí sua indiscutível importância para nós, o que, todavia, ainda não é percebida por todos. Nesse pensamento, Tundisi (2003, p. 02) assegura que, embora dependam da água para a sobrevivência e para o desenvolvimento econômico, as sociedades humanas poluem e degradam este recurso.

\section{Ciclo hidrológico e distribuição de água doce noplaneta}

Conceituando ciclo hidrológico, Tundisi (2011, p. 29) o aponta como o princípio unificador fundamental de tudo o que se refere à água no Planeta, elucidando que esse ciclo é o modelo pelo qual se representam a interdependência e o movimento contínuo da água nas fases sólida, líquida e gasosa, pois toda a água do planeta está em contínuo movimento cíclico entre as reservas sólida, líquida e gasosa, com a ressalva de que, logicamente, a de maior interesse é a líquida, fundamental para o uso e a satisfação das necessidades do ser humano e de todos os organismos vivos, animais e vegetais.

Conforme visto, as propriedades específicas da água permitem seu movimento entre a superfície da Terra, as zonas profundas saturadas dos solos, os oceanos e a atmosfera, num processonatural,denominadociclohidrológico,queédesencadeadopelaenergiasolar.(CECH, 2013, p. 23).

Esse movimento cíclico da água no globo terrestre, do mar para a atmosfera, da atmosfera para a terra e, subsequentemente, de volta para o mar, é explicado por Caponera (2011, p. 05): 
Com o calor do sol, a água dos oceanos e de outros corpos d'água evaporam e sobem para a atmosfera. A água atmosférica se condensa formando as nuvens, que são levadas pelo vento e, depois, descem à terra em forma de chuva, neve, granizo ou orvalho, parte da qual evapora imediatamente, parte é absorvida pelas plantas (evapotranspiração), parte se infiltra no solo para formar aquíferos subterrâneos e parte flui na superfície (fluxo de água) da terra,formandocursosd'água,rios,lagos,pântanosetc.,osquais,porsuavez, fluem para o mar.Do mar,o ciclo hidrológico começa denovo.

Neste processo, pode-se constatar seus componentes fundamentais: a precipitação, o escoamento, o armazenamento de águas superficiais e subterrâneas, a evaporação/transpiração e a condensação. A precipitação é um termo geral que descreve todas as formas de água que caem da atmosfera ao solo, embora nem sempre seja possível conhecer a quantidade de água disponível na superfície, no subsolo ou na atmosfera (CAPONERA, 2011, p. 06). A precipitação, ao atingir a superfície da Terra, pode se tornar água de escoamento superficial,

água superficial armazenada ou água nos oceanos, ou mesmo pode evaporar e retornar imediatamente à atmosfera. (CECH' 2013, p. 22).

A água no ciclo hidrológico não é criada nem destruída, ela simplesmente muda de estado e de lugar. Nos oceanos estão 97,5\% de toda a água existente no ciclo hidrológico da Terra, e os 2,5\% remanescentes são encontrados nas calotas polares congeladas, nas águas subterrâneas, nos rios, nos lagos, nas lagoas, em wetlands ${ }^{2}$, ou na umidade da atmosfera. (CECH'2013, p. 22).

Mas o ciclo hidrológico não é fechado. Conforme Tundisi (2011, p. 30), até o final da década de 1980 acreditava-se que a quantidade de água permanecera sempre a mesma desde o início da Terra e nenhuma água entraria no planeta Terra a partir do espaço exterior nem nenhuma água o deixaria. No entanto, descobertas recentes sugerem "bolas de neve" de 20 a 40 toneladas, denominadas por cientistas de "pequenos cometas", provenientes de outras regiões do sistema solar, que podem atingir a atmosfera da Terra. Essas chuvas de "bolas de neve" vaporizam-se quando se aproximam da atmosfera terrestre e podem ao longo de 10 mil anos ter acrescentado 3 trilhões de toneladas de água no planeta.

O fato é que a Terra está coberta por esse elemento, tanto que por isso chamada de planeta azul. A água está em sua maior parte nos oceanos e mares, restando apenas pequena parcela de água doce para consumo e sobrevivência dos habitantes do planeta, cujo elo regulador de equilíbrio é justamente o ciclo hidrológico. 
O problema é que a distribuição da água não é homogênea. Em algumas áreas, há graves problemas de escassez. Esse é o resultado das alterações do ciclo hidrológico em suas diversas etapas, variando de acordo com a região do planeta, a produzir alterações na hidrodinâmica e na qualidade da água como consequência das mudanças globais (TUNDISI, 2011, p. 91), mudanças essas que têm direta implicação no conceito de ciclo hidrológico como "circulação natural da água dentro, sobre e acima da Terra" (AMORIM, 2015, p. 22) independentemente da ação do homem, redefinindo a noção de ciclo em relação à água e estabelecendo um processo no qual a água e a sociedade criam e recriam, ao longo da história do planeta e do homem, um novo ciclo, chamado pelos especialistas de ciclohidrossocial ${ }^{3}$.

\footnotetext{
${ }^{2} \mathrm{O}$ termo Wetlands é utilizado para caracterizar vários ecossistemas naturais que ficam parcial ou totalmente inundadosduranteoano.FBDS.FundaçãoBrasileiraparaoDesenvolvimentoSustentável.Controledequalidade de água através de sistemas Wetlands construídos. Disponível em <http://www.fbds.org.br/Apresentacoes/Controle_Qualid_Agua_Wetlands_ES_out06.pdf> Acesso em 26 dez. 2015.

${ }^{3} \mathrm{O}$ estudo do ciclo hidrossocial tem seu ponto de partida os estudos de LNTON, J.; BUDDS, J. The hydrosocial cycle. Defining and mobilizing a relational-dialectical approach to water, mencionado por AMORIM, 2015. p. 22.
} 


\section{A encases da água e a necessidade de sua proteção}

Em razão das peculiaridades relativas ao clima, a água não é distribuída homogeneamente pelo planeta. Enquanto algumas áreas do mundo podem ter excesso deágua, em outras partes pode haver carência, dicotomia que pode causar impactos extremamente significativosnautilizaçãoenaprópriaqualidadedaáguadoce.Masoclimanãoéúnicomotivo dessa dificuldade. Viegas (2005, p. 27) aponta a poluição ambiental como o principal fator da crise da água, a refletir nos demais recursos naturais e assim afetar todo o equilíbrio planetário "na medida em que, ao longo da história do desenvolvimento dos povos, e sobretudo a partir da Revolução Industrial, a preocupação da humanidade centrou-se fundamentalmente na produção,semmaiorescuidadoscomapreservaçãodomeioambientee,consequentemente,de seusrecursos".

A atuação humana sobre o clima e sobre o ciclo hidrológico, a lhes impor graves alterações, está diretamente ligada à crise e à escassez da água. Nesse sentido, Tundisi (2011, p. 42-43) explica que,

[...]asinterferênciasdasatividadeshumanasnociclohidrológicoocorremem muitospaísesdetodososcontinentes.Osimpactosdessaintervençãonociclo variam para cada região ou continente. De modo geral, esses impactos são:a) construção de reservatórios para aumentar as reservas de água e impedir o escoamento; b) uso excessivo de águas subterrâneas e importação deágua e, c) transposição de águas entre bacias hidrográficas. As atividades humanas alteram, portanto, o padrão espacial de vazão natural - em alguns casos, em mais de $70 \%$.

Essas interferências da ação humana ao longo do tempo provocaram significativas mudanças nos fluxos naturais, dificultando o acesso à água em diversas regiões do planeta. A exemplodisso,em material divulgada pelas Organizações das Nações Unidas-ONUemmarço de 2015 por um levantamento global da Unicef e da World Health Organization (WHO), uma em cada três pessoas no mundo - cerca de 2,4 bilhões de indivíduos - ainda não têm acesso a serviços de saneamento básico e de águapotável.

Caubet (2006, p. 21) revela que as projeções para o futuro são dramáticas. Estima-se que a demanda de água dobrará a cada 20 anos, ou seja, duas vezes mais rápido do que o crescimento demográfico mundial, donde segue a previsão de que em 2025 a superação da demanda em relação à oferta será de $56 \%$. Se assim for, 4 bilhões de pessoas não terão os suprimentosnecessáriosparaassuasnecessidadesbásicas, edoisterçosdaspessoasnemsequer terão acesso à águapotável. 
Por força da importância da água para a vida no planeta e diante da quantidade disponível de água doce, a Organização das Nações Unidas - ONU, por meio de diversos encontros, buscou estabelecer metas e acordos com o fim de garantir a vida com dignidade.

O relatório da ONU publicado pelo Programa Mundial de Avaliação dos Recursos Hídricos (World Water Assessment Programme, em inglês), liderado pela UNESCO OrganizaçãodasNaçõesUnidasparaaEducação,aCiênciaeaCultura,pormeioda $U N$-Water (mecanismo interagencial das Nações Unidas para assuntos relacionados à água e questões de saneamento),enfatizou,nomomentoemqueasNaçõesUnidaspreparavamaadoçãodenovos Objetivos de Desenvolvimento Sustentável, a necessidade urgente de mudar a forma como usamos e gerenciamos esse recursovital.

Esse relatório assegura que até 2030 o planeta enfrentará um déficit de água de 40\%, salvosemelhoradadramaticamenteagestãodessepreciosorecursonatural.Essaéaconclusão inevitáveldoRelatóriodasNaçõesUnidassobreoDesenvolvimentodeÁgua2015-Águapara ummundosustentável,lançadoem20demarçodesteano,emNovaDeli(Índia),emcelebração ao Dia Mundial da Água (22 de março). (UNESCO,2015).

Nas palavras da diretora-geral da UNESCO, Irina Bokova,

Os recursos hídricos são um elemento-chave nas políticas de combate à pobreza,masporvezessãoameaçadospeloprópriodesenvolvimento.Aágua influencia diretamente o nosso futuro, logo, precisamos mudar a forma como avaliamos, gerenciamos e usamos esse recurso, em face da sempre crescente demandaedasuperexploraçãodenossasreservassubterrâneas.Esseéoapelo feito pela edição mais recente do Relatório Mundial das Nações Unidassobre Desenvolvimento de Recursos Hídricos. As observações do Relatório são oportunas, porque a comunidade internacional precisa elaborar um novo programa de desenvolvimento para substituir os Objetivos de Desenvolvimento do Milênio. (UNESCO,2015) 
$\mathrm{Na}$ mesma esteira, Michel Jarraud, presidente da $U N$-Water e secretário-geral da Organização Meteorológica Mundial, disse que já existia um “consenso internacional de que água e saneamento são essenciais para que muitos dos Objetivos de Desenvolvimento do Milêniosejamatingidos",dêsqueesseselementos“"estãoindissoluvelmenteligadosaquestões como mudança climática, agricultura, segurança alimentar, saúde, energia, equidade, questão de gênero e educação". (UNESCO,2015).

Com um olhar direcionado para esse fim e visando a uma solução para esse desafio, a ONU traçou um plano de ação para as pessoas, para o planeta e para a prosperidade, chamada Agenda 2030 para o Desenvolvimento Sustentável, que possui 17 objetivos e 169 metas,que buscam um equilíbrio entre o suprimento ea demanda da água, alémdeconcretizar os direitos humanos de todos, integrados e indivisíveis, com equilíbrio nas três dimensões do desenvolvimento sustentável: a econômica, a social e a ambiental.

Dentre esses objetivos, notadamente o número 6 visa a "Assegurar a disponibilidade e gestão sustentável da água e saneamento para todos”, que consiste em:

6.1 Até2030,alcançaroacessouniversaleequitativoaáguapotávelesegura paratodos.

6.2 Até 2030, alcançar o acesso a saneamento e higiene adequados e equitativos para todos, e acabar com a defecação a céu aberto, com especial atenção para as necessidades das mulheres e meninas e daqueles em situação devulnerabilidade.

6.3 Até2030,melhoraraqualidadedaágua,reduzindoapoluição,eliminando despejo e minimizando a liberação de produtos químicos e materiais perigosos, reduzindo à metade a proporção de águas residuais não tratadas e aumentandosubstancialmenteareciclagemereutilizaçãoseguraglobalmente.

6.4 Até2030,aumentarsubstancialmenteaeficiênciadousodaáguaemtodos os setores e assegurar retiradas sustentáveis e o abastecimento de água doce para enfrentar a escassez de água, e reduzir substancialmente o número de pessoas que sofrem com a escassez deágua.

6.5 Até 2030, implementar a gestão integrada dos recursos hídricos em todos os níveis, inclusive via cooperação transfronteiriça, conformeapropriado.

6.6 Até 2020, proteger e restaurar ecossistemas relacionados com a água, incluindo montanhas, florestas, zonas úmidas, rios, aquíferos elagos.

6.a Até2030,ampliaracooperaçãointernacionaleoapoioàcapacitaçãopara ospaísesemdesenvolvimentoematividadeseprogramasrelacionadosàágua esaneamento,incluindoacoletadeágua, adessalinização, aeficiêncianouso água, o tratamento de efluentes, a reciclagem e as tecnologias dereuso.

6.b Apoiar e fortalecer a participação das comunidades locais, para melhorar a gestão da água e do saneamento. (ONU,2016). 
Os países estão longe de atingir essas metas. O Brasil, detentor da maior parte da água do planeta, cerca de $12 \%$ da água doce superficial, possui responsabilidade na mesma proporção. Afinal, somente 2,5\% da água do planeta está disponível como água doce, e destes 2,5\%-querepresentam $100 \%$ detodaáguadocedoplaneta-cercade $68,9 \%$ estãocongelados nascalotaspolaresegeleiras,emestadosólido,29,9\%estãoconfinadosnaságuassubterrâneas, 0,9\% naságuasdosrioselagose $0,3 \%$ emoutrosreservatórios. Adisponibilidadedaáguadoce em estado líquido é muito pequena, e é dessa pequena fração que toda a humanidade depende parasobreviver.

De acordo com a FAO (Food and Agriculture Organization of the United Nations), das águas que correm em nossos rios, o Brasil detém o dobro de todos os rios da Austrália e da Oceania, é $42 \%$ superior ao da Europa e $25 \%$ maior do que os do continente africano. Além disso, aproximadamente $90 \%$ do território brasileiro recebe chuvas abundantes durante o ano, o que favorece a formação de uma extensa e densa rede de rios. (UNILEVER, 2015). 
Nesse particular, merece destaque o Aquífero Guarani, reservatório de águas subterrâneas de 1 milhão e 200 mil quilômetros quadrados que se estende pelos territórios não só do Brasil, que detém sua maior parte $\left(840.000\right.$ km²), mas também do Uruguai $\left(58.500 \mathrm{~km}^{2}\right)$ edaArgentina $\left(355.000 \mathrm{~km}^{2}\right)$,compreendendoumaáreaequivalenteàdospaísesdaInglaterra, França e Espanha juntos. (FIORILLO, 2007, p.296).

Oterritóriobrasileiro,segundoDantaseSchmitt(2015), apresentabaciashidrográficas deenormerelevância,aexemplodoAmazonas,doTocantins,doSãoFrancisco,doParaná,do Paraguai e do Uruguai, possuindo a maior rede hidrográfica do mundo, com extensas reservas subterrâneas recentementedescobertas.

\begin{abstract}
Recentes descobertas apontam, por exemplo, a presença de um "oceano subterrâneo" de água doce na Amazônia. Essa reserva, também conhecida como Aquífero da Amazônia, apresenta um volume 3,5 vezes maior do que o Aquífero Guarani, que sempre se apresentou como a principal reserva subterrânea de água doce do mundo. (DANTAS; SCHMITT, 2015).
\end{abstract}

Mesmo com esse avantajado quadro, o Brasil possui populações que não recebem água limpa,apesardaevoluçãonascondiçõesdosúltimos25anosapontadapelorelatóriodaUnicef: “94\%dapopulaçãotemacessoaserviçosdeáguapotável.Nascidades, essepercentualalcança 98\%, contra $92 \%$ em 1990. Entre a população rural, o avanço foi bem mais expressivo nos últimos 25 anos: apenas 38\% acessavam redes de água limpa nestas regiões, contra $70 \%$ em 2015".Emcontrapartida,nomundo1,7bilhãodepessoaspassaramateracessoaáguapotável desde 1990, mas ainda 884 milhões de pessoas em todo o mundo não têm acesso a fontes de águapotáveldequalidade.(ONU,2015).Eaquelesmaisafetadossãoaspessoasdebaixarenda, os desfavorecidos e as mulheres. Ao mesmo tempo, o planeta nunca esteve tão sedento. Para responder às necessidades de uma população em constante crescimento, os setores de agricultura e energia precisam continuar a produzir cada vez mais. De agora até 2050, a agricultura, que consome a maior parte da água, precisará produzir mundialmente $60 \%$ a mais de comida, $100 \%$ a mais em países em desenvolvimento. (UNESCO,2015).

Com uma demanda de bens manufaturados quê soa umenta, apressão sobre os recursos hídricos é maior. A previsão é de que entre 2000 e 2050 a demanda da indústria por água crescerá até $400 \%$.

Enquanto isso, $20 \%$ das fonts mundiais de água subterranean já estão super exploradas e ainda não existe um gerenciamento sustentável desses recursos naturais. A 
irrigaçãointensade plantações, a liberação descontrolada de pesticidas e de produtos químicos em cursos d'águae

a ausência de tratamento de esgoto - o que atinge 90\% das águas residuais em países em desenvolvimento - são provas dessa situação.

De todo modo, com base nos dados apontados, os países comprometidos com a Agenda 2030,notadamente o Brasil, precisam rever suas políticas e fazer uso de mecanismos de gestão das águas a partir da grande disponibilidade hídrica distribuída nas suas baciashidrográficas.

\section{Gestão sustentável daágua}

A água é um elemento de extrema importância em todos os aspectos da atividade humana. Sua disponibilidade é condição da manutenção da vida na Terra. A terra irrigada produz alimentos, plantas, florestas, e por isso é um bem necessário e fundamental. Todas as civilizações que passaram pelo planeta precisaram, cada uma ao seu tempo, desenvolver métodos e técnicas para utilização da água.

A gestão ambiental, no atual contexto, vem assumindo grande importância e repercussão, como uma resposta à demanda da sociedade contemporânea, segundo enfatizam Medeiros, Giordano e Reis (2012, p. 375): 
O homem está em um momento de sua história evolutiva em que énecessária uma mudança de paradigma a respeito da sua inter-relação com o meio ambiente e seu uso, pois os recursos naturais não são mais capazes de manter a sustentabilidade dos ecossistemas e, ao mesmo tempo, suprir a demanda cada vez mais intensa de consumo imposta pelos padrões de vidamoderna.

A gestão ambiental volta-se para atender a realidade ambiental na incumbência de aplicaçãodasnormastécnicas,jurídicas,administrativas,econômicas,sociais,éticasepolíticas para a salvaguarda dos ecossistemas e de seus recursos, com o intuito de garantir o prosseguimento da vida e da sua boa qualidade em todos os tempos e lugares do planeta. (MILARÉ,2014).

Apartirdaí,agestãodaágua,comoexpressão,podesercompreendida,naspalavrasde Magalhães Junior (2014), como a atividade analítica e criativa voltada à formulação de princípios e diretrizes, ao preparo de documentos orientadores e normativos, à estruturação de sistemas gerenciais e à tomada de decisões que têm por objetivo final promover o inventário, uso, controle e proteção da água. Explica o autor a importância desse processo da seguinte forma,

[...] o processo de gestão permite o equacionamento e resolução das questões de escassez relativa da água, bem como a busca do seu uso adequado, viabilizando a harmonização das demandas e da oferta de água em uma unidade territorial. [...] envolve o processo de planejamento, o qual compreende uma sistemática de organização e compatibilização dos usos múltiplos da água visando à tomada de decisões em um contexto de trabalho permanente de acompanhamento e avaliação das ações realizadas. (MAGALHÃES JUNIOR, 2014, p. 66). 
Entendem Medeiros, Giordano e Reis (2012) que os recursos naturais podem ser utilizadosdesdequedessautilizaçãonãocesseacapacidadedoambientedecontinuarprovendo esses mesmos recursos, citando comoexemplo,

[...] a manutenção do ciclo hidrológico, tão essencial para toda a biosfera e paraosprocessosdomeiofísico,oqualpodeserafetadopelolançamentosde gases contribuintes para o efeito estufa, alterando a quantidade delocalização de precipitações, bem como pelo desmatamento e uso do solo agrícola sem proteção a processos erosivos, que afetam a velocidade de escoamento superficial, diminuindo a capacidade de infiltração de água no solo e em decorrência de manutenção e reposição de água em cursos fluviais. (MEDEIROS; GIORDANO; REIS, 2012, p.375).

Essa interferência do homem nas questões ambientais, em especial na água em seus múltiplosusos,vemcausandoproblemasambientais,comoconseguintecrescimentodecustos econômicosesociais.Porissoagestãosustentáveldaáguaestádirecionadaaoatendimentodas necessidades das presentes e das futuras gerações, na linha do conceito de desenvolvimento sustentável (MAGALHÃES, 2014, p. 66). Portanto, “a noção de gestão sustentável da água, disseminada nos anos 90, está ligada ao objetivo de universalização do acesso contínuo da água" (MEDEIROS, 2012, p.375).

Não obstante esses diferentes conceitos colacionados, o que melhor se afeiçoa ao tema é trazido por Medeiros, Giordano e Reis (2012, p. 375), quando cita Souza:

\footnotetext{
A gestão ambiental pode ser entendida [...] como conjunto de procedimentos que visam à conciliação entre desenvolvimento e qualidade ambiental. Essa conciliaçãoaconteceapartirdaobservânciadacapacidadedesuportedomeio ambiente e das necessidades identificadas pela sociedade civil ou pelo governo [...] ou ainda por ambos [...]. [...] encontra na legislação, na política ambiental e em seus instrumentos e na participação da sociedade suas ferramentas deação.
}

Detentor da maior reserva de água doce do planeta, no Brasil grassou com força aideia da inesgotabilidade desse recurso, cujo equívoco, há muito reconhecido, terminou porpermitir a conclusão, aliás inexorável, de que a "gestão e a proteção pública destes recursos devem ser empregadasafimdegarantirumsistemadeutilizaçãoeficiente,capazdegarantiramanutenção da quantidade, qualidade e distribuição desses recursos”(DANTAS; SCHMITT,2015).

No Brasil, a gestão da água é representada pelo Plano Nacional de Recursos Hídricos, 
no qual o processo de planejamento do uso da água é desenvolvido a nível nacional, estadual e municipal.

\subsection{O Regime jurídico da gestão das águas brasileiras}

No Brasil, a gestão ambiental dos recursos hídricos se deu com a instituição da Política Nacional de Recursos Hídricos - PNRH, objeto da Lei no 9.433, de 8 de janeiro de 1997, que criou o Sistema Nacional de Gerenciamento de Recursos Hídricos.

A lei regulamenta o art. 21, XIX, da Constituição da República Federativa do Brasil de 1988, que aponta a competência da União para instituir o Sistema Nacional de Gerenciamento de Recursos Hídricos - SNGRH e definir critérios de outorga de direitos de seu uso, com o objetivo de exercer uma gestão integrada e descentralizada das águas, contando com a participação do Poder Público, dos usuários e das comunidades, elegendo a bacia hidrográfica como a unidade territorial para a implantação da PNRH e para atuação do SNGRH.

Nesse sentido, estabelece o art. $1^{\circ}$ da Lei $n^{\circ} 9.433 / 1997$ :

Art. $1^{\circ}$ A Política Nacional de Recursos Hídricos baseia-se nos seguintes fundamentos:

I - a água é um bem de domíniopúblico;

II - a água é um recurso natural limitado, dotado de valoreconômico;

III - em situações de escassez, o uso prioritário dos recursos hídricos é o consumo humano e a dessedentação deanimais;

IV - a gestão dos recursos hídricos deve sempre proporcionar o uso múltiplo daságuas;

V - a bacia hidrográfica é a unidade territorial para implementação da Política Nacional de Recursos Hídricos e atuação do Sistema Nacionalde Gerenciamento de RecursosHídricos;

VI - a gestão dos recursos hídricos deve ser descentralizada e contarcom a participação do Poder Público, dos usuários e das comunidades. (grifos meus)

Comentam Medeiros, Giordano e Reis (2012, p. 378) que pela primeira vez são estabelecidas políticas vinculadas aos limites físicos dos recursos naturais, assim as bacias hidrográficas, deixando-se de considerar apenas limites administrativos, para mais de se determinar a participação dos usuários e das comunidades nos processos de gestão.

Quanto à descentralização das decisões, prevista no inciso VI do art. $1^{\circ}$ da lei referida, Granziera(2014,p.152)comentaqueessa“"estruturaçãodosistemanacionaldegerenciamento de recursos hídricos é, verdadeiramente, uma das necessidades que se configuram mais 
prioritária se urgentes para a coletividade brasileira",pois visa as segurara os cidadãos que a água se torne acessível a todos, tanto em quantidade quanto em qualidade.

O processo de gestão é representado pelo Plano Nacional de Recursos Hídricos conforme art. $5^{\circ}$ da lei, "São instrumentos da Política Nacional de Recursos Hídricos: I - os Planos de Recursos Hídricos" -, que são planos diretores que visam a fundamentar e orientara implementação da Política Nacional de Recursos Hídricos e o gerenciamento dos recursos hídricos, conforme arts. $6^{\circ}$ e $7^{\circ}$ da Lei $n^{\circ} 9.433 / 1997$.

A Le imencionada também criou,em seu art.32,o"Sistema Nacional de Gerenciamento de Recursos Hídricos", com o objetivo, dentre outros, de "coordenar a gestão integrada das águas", o que, para Granziera (2014, p. 152), configurou grande novidade da legislação, pois esse sistema, a que cabe implementar a PNRH,constitui 
[...] ]oconjuntodeórgãoseentidades,governamentaisounão,envolvidoscom a aplicação dos instrumentos da Política de Recursos Hídricos, visando o alcance dos objetivos propostos. A novidade dos sistemas legalmente estabelecidosevinculadosàexecuçãodepolíticaspúblicas,comoéocasodo meioambiente,refere-seàpossibilidadedeoutraspessoas,quenãoapenasos órgãos e entidades públicas, detentoras do domínio dos bens envolvidos, participarem do seugerenciamento.

Esse conjunto de órgãos integram as instituições da gestão dentro das Políticas Nacionais de Recursos Hídricos, conforme se verá sequencialmente.

Trata-se, aí, de modelo regulatório afeito à "fase participativa" do Direito Ambiental, sobre o que Garcia (2015) esclarece:

\begin{abstract}
A proteção ambiental não poderia ficar única e exclusivamente nas mãos dos poderes públicos, mas sim havia a necessidade de integração de toda sociedade. Sendo assim, nessa fase do Direito Ambiental houve uma valorização muito grande à informação para tomada de conscientização das pessoas da necessidade da proteção ambiental.
\end{abstract}

\title{
4.1.1 Instituições dagestão
}

O SNGRH, com sua gestão descentralizada, é composto, conforme art. 33 da Lei ${ }^{\circ}$ 9.433/1997, por um conjunto de órgãos e entidades que deverão atuar de forma articulada e coordenada na gestão das águas:

Art. 33. Integram o Sistema Nacional de Gerenciamento de Recursos Hídricos:

I - o Conselho Nacional de Recursos Hídricos;

I-A - a Agência Nacional deÁguas; 
II - os Conselhos de Recursos Hídricos dos Estados e do Distrito Federal;

III - os Comitês de BaciaHidrográfica;

IV - os órgãos dos poderes públicos federal, estaduais, do Distrito Federal e municipais cujas competências se relacionem com a gestão de recursos hídricos;

V - as Agências deÁgua.

O Conselho Nacional de Recursos Hídricos - CNRH, os Conselhos Estaduais de Recursos Hídricos e os Comitês de Bacia Hidrográfica são colegiados constituídos por representantesdosgovernosedasociedadecivilparaagestãodosrecursoshídricos,valedizer, "todos os setores interessados decidem como planejar e gerenciar de forma participativa o uso da água, compatibilizando os seus diversos usos: abastecimento, produção de energia, uso industrial, irrigação, transporte, entre outros” (GRAF apud, FREITAS, 2008, p.73).

Segundo o Ministério do Meio Ambiente (BRASIL, 2015), o CNRH desenvolveregras demediaçãoentreosdiversosusuáriosdaágua,sendoassimumdosgrandesresponsáveispela implementação da gestão dos recursos hídricos no país. Por articular a integração das políticas públicas no Brasil, é reconhecido pela sociedade com o orientador para um diálogo transparente no processo de decisões no campo da legislação de recursoshídricos.

O CNRH tem como competências, dentre outras, analisar propostas de alteração da legislação pertinente a recursos hídricos, estabelecer diretrizes complementares para implementação da Política Nacional de Recursos Hídricos, promover a articulação do planejamento de recursos hídricos com os planejamentos nacional, regionais, estaduais e dos setores usuários, arbitrar conflitos sobre recursos hídricos, deliberar sobre projetos de aproveitamento de recursos hídricos cujas repercussões extrapolem o âmbito dos estados em que serão implantados, aprovar propostas de instituição de comitês de bacia hidrográfica, estabelecer critérios gerais para a outorga de direito de uso de recursos hídricos e para a cobrança por seu uso, e, ainda, aprovar o Plano Nacional de Recursos Hídricos e acompanhar sua execução, tudo segundo o art.35 da Lei no 9.344/1997.

Disciplina dos pelosarts.37a40daPNRH, os Comitês de Bacia Hidrográfica, principais órgãos gestores de bacias hidrográficas, são organismos colegiados de caráter técnico 
epolítico. A composição diversificada e democrática desses Comitês contribui para que todos os setores da sociedade com interesse sobre a água na bacia tenham representação e poder de decisão sobresuagestão. Os membros que compõem o colegia do são escolhidos entre seus pares, sejam eles dos diversos setores usuários de água, das organizações da sociedade civil ou dos poderes públicos. Suas principais competências são aprovar o Plano de Recursos Hídricos da Bacia, arbitrar conflitos pelo uso da água em primeira instância administrativa, estabelecer mecanismos e sugerir os valores da cobrança pelo uso da água. (BRASIL, 2015).

Quanto às Agências de Água, funcionam como secretarias executivas dos comitês de bacias hidrográficas e têm por atribuição, conforme dispõe o art. 44 da lei:

I - manter balanço atualizado da disponibilidade de recursos hídricos em sua área de atuação; II - manter o cadastro de usuários de recursos hídricos; III efetuar, mediante delegação do outorgante, a cobrança pelo uso de recursos hídricos; IV - analisar e emitir pareceres sobre os projetos e obras a serem financiados com recursos gerados pela cobrança pelo uso de Recursos Hídricos e encaminhá-los à instituição financeira responsável pela administraçãodessesrecursos; $\mathrm{V}$-acompanharaadministraçãofinanceirados recursos arrecadados com a cobrança pelo uso de recursos hídricos em sua áreadeatuação;VI-geriroSistemadeInformaçõessobreRecursosHídricos emsuaáreadeatuação;VII-celebrarconvêniosecontratarfinanciamentose serviçosparaaexecuçãodesuascompetências; VIII-elaborarasuaproposta orçamentária e submetê-la à apreciação do respectivo ou respectivos Comitês deBaciaHidrográfica;IX-promoverosestudosnecessáriosparaagestãodos recursos hídricos em sua área de atuação; X - elaborar o Plano de Recursos Hídricos para apreciação do respectivo Comitê de Bacia Hidrográfica; XI propor ao respectivo ou respectivos Comitês de Bacia Hidrográfica: a) o enquadramento dos corpos de água nas classes de uso, para encaminhamento ao respectivo Conselho Nacional ou Conselhos Estaduais de Recursos Hídricos, de acordo com o domínio destes; b) os valores a serem cobrados pelousoderecursoshídricos;c)oplanodeaplicaçãodosrecursosarrecadados com a cobrança pelo uso de recursos hídricos; d) o rateio de custo das obras de uso múltiplo, de interesse comum oucoletivo 
Como a União tem competência privativa para legislar sobre águas, cabe aos Estados e Municípios a sua gestão descentralizada por delegação, de sorte que "trata-se de um sistema que congrega centralização legislativa e gestão descentralizada e participativa, que pressupõe uma articulação eficiente entre todos os integrantes deste sistema” (GRAF apud, FREITAS, 2008, p. 74).

Porfim,aLein ${ }^{\circ} 9.984 / 2000$,emseuart.3ํ, criouaAgênciaNacionaldeÁguas-ANA, uma autarquia sob regime especial, com autonomia administrativa e financeira, vinculada ao Ministério do Meio Ambiente, com a finalidade de implementar, em sua esfera de atribuições, aPolíticaNacionaldeRecursosHídricos, integrandooSistemaNacionaldeGerenciamentode RecursosHídricos.

Para que o gerenciamento dos recursos hídricos seja efetivo, não basta a previsão legislativa. Ainda que o PNRH constitua relevante marco inicial, será necessário que os princípios e objetivos assim traçados sejam alcançados com a participação de todos os envolvidos.

O Brasil possui diversos projetos ambientais cujo objetivo final é a gestão da água. O Ministério do Meio Ambiente patrocina projetos que visam a amenizar os problema $\mathrm{s}$ de acesso, saneamento e higiene, amelhoria da qualidade da água para uso em todos os setores, aretirada sustentável, proteção e restauração de ecossistemas ea o fortalecimento das comunidades. Esses projetos, porém, só atingirão seus respectivos objetivos se todos os partícipes do SNGRH e a própria população se conscientizarem da necessidade da melhora na gestão da água diante das previsões de escassez desse recurso natural em curtoprazo. 


\section{Considerações Finais}

A pesquisas e propôsa investigar os aspectos jurídicos da gestão da água do ceno Brasil como um caminho para o alcance da Agenda 2030.

Os estudos apontaram que a escassez dos recursos naturais, em especial a água,é objeto de preocupação mundial, o que levou a Organização das Nações Unidas alançara Agenda 2030 para por meio dela alcançar 17 Objetivos de Desenvolvimento Sustentável.

O Brasil, atento a diretrizes internacionais e após diversos encontros sobre meio ambiente e antevendo o agravamento da escassez da água doce naTerra, firmou seu marco regulatório da gestão de água. A Constituição da República, de 1988, dispôs em seu art. 21, XIX,que cabeà União instituir sistema nacional de gerenciamento de recursos hídrico se definir critérios de outorga de direitos de seu uso. A partir daí, em 1998 foi instituída a Política Nacional de Recursos Hídricos e criado o Sistema Nacional de Gerenciamento de Recursos Hídricos, com o objetivo de exercitar gestão integrada e descentralizada das águas com a participação do Poder Público, dos usuários e dascomunidades.

No atual momento, a disponibilidade de água doce distribuída nas bacias hidrográficas do país, marcadas por diferenças regionais e sociais, não deixa dúvidas de que os desafios da gestão da água são grandes, até pelo fato de o Brasil já não ter cumprido os Objetivos do Milênio, dentre eles o de, com a finalidade de promover o desenvolvimento sustentável, até 2015 reduzir pela metade a população sem acesso a saneamento básico.

Para que a Política Nacional de Recursos Hídricos seja efetiva, não só o Poder Público mas também a sociedade deve assumir a responsabilidade de zelar pela garantia da quantidade e da qualidade da água, de modo a possibilitar o acesso de todos a seus múltiplos usos.

AindaqueoBrasilestejadotadodeinstrumentosjurídicoscapazesdepermitiroalcance dos objetivos lançados, o cumprimento do Objetivo $\mathrm{n}^{\mathrm{o}} 6$ dos Objetivos de Desenvolvimento Sustentável exigirá, antes de tudo, a implementação de programas de conscientização. Afinal, o até aqui exposto demonstra a necessidade de mudanças substanciais nos governose na 
sociedade para efetivo planejamento e gerenciamento na utilização da água.

\section{REFERÊNCIAS}

AMORIM, José Alberto Alves. Direito das águas: o regime jurídico da água doce no direito internacional e no direito brasileiro. 2. ed. São Paulo: Atlas, 2015.

BARTH, Flávio Terra. Modelos para gerenciamento de recursos hídricos. São Paulo: Nobel ABRH, 1987.

BIANCHI, Adriana. Desafios institucionais no setor de água: In: VIEGAS, Eduardo Coral. Visão jurídica da água. Porto Alegre: Livraria do advogado, 2005.

BRASIL. Ministério do Meio Ambiente. Comitês da Bacia Hidrográfica. Disponível em <http://www.cbh.gov.br/GestaoComites.aspx> Acesso em 29 dez. 2015.

BRASIL. Ministério do Meio Ambiente. Conselho Nacional de Recursos Hídricos. Disponível em <http://www.mma.gov.br/agua/recursos-hidricos/sistema-nacional-degerenciamento-de-recursos-hidricos> Acesso em 29 dez. 2015.

CAPONERA, Dante A. Princípios de direito e administração de águas nacionais e internacionais. 2. ed. Rio de Janeiro: Synergia: IVIG/COPPE/UFRJ, 2011.

CASARIN, Fátima; SANTOS, Monica dos. Água: o ouro azul. Rio de Janeiro: Garamond, 2011.

CAUBET, Christian Guy. A água, a lei, a política... E o meio ambiente? Curitiba: Juruá, 2006.

CECH, Thomas V. Recursos hídricos: história, desenvolvimento, política e gestão. Rio de Janeiro: LTC, 2013.

DANTAS, Marcelo Buzaglo; Schmitt, Guilherme Berger. Os desafios da sustentabilidade ambiental na gestão dos recursos hídricos: o papel do direito e do poder público no Brasil e na Espanha. Disponível em $><$ http://siaiapp28.univali.br/lstfree.aspx?type=ebook\&id=4 > Acesso em 29 dez. 2015.

FBDS.FundaçãoBrasileiraparaoDesenvolvimentoSustentável.Controledequalidadede água através de sistemas Wetlands construídos. Disponível em <http://www.fbds.org.br/Apresentacoes/Controle_Qualid_Agua_Wetlands_ES_out06.pdf> Acesso em 26 dez. 2015.

FIORILLO, CELSO Antonio Pacheco. Curso de direito ambiental brasileiro. 8. ed. São Paulo: Saraiva, 2007. 
GARCIA, Denise Schmitt Siqueira. (org.) Debates sustentáveis: análise multidimensional e governança ambiental. Disponível <http://siaiapp28.univali.br/lstfree.aspx?type=ebook\&id=4> Acesso em 27 dez. 2015.

GRAF,AnaCláudiaBento.Atuteladosestadossobreágua.In:FREITAS, VladimirPassosde. Águas: aspectos jurídicos e ambientais. 3. ed. Curitiba: Juruá, 2008.

GRANZIERA, Maria Luiza Machado. Direito de águas: disciplina jurídica das águas doces. 4. ed. São Paulo: Atlas, 2014.

MAGALHÃES JÚNIOR, Antonio Pereira. Indicares ambientais e recursos hídricos: realidade e perspectivas para o Brasil a partir da experiência francesa. 6. ed. Rio de Janeiro: Bertrand Brasil, 2014.

MEDEIROS, Gerson Araújo; GIORDANO, Lucilia do Carmo; REIS, Fábio Augusto Gomes Vieira.Gestãoambiental.In:Meioambiente:sustentabilidade.PortoAlegre:Bookman,2012.

MILARÉ, Edis. Direito ao ambiente. 9. ed. São Paulo: Revista dos Tribunais, 2014.

ONU. Organização das Nações Unidas. Objetivo 6: Garantizar la disponibilidad de agua y su gestiónsostenibleyelsaneamientoparatodos.Disponívelem: $<$ http://www.un.org/sustainable development/es/water-and-sanitation/> Acesso em 27 dez.2015.

ONU BR. Nações Unidas no Brasil. Objetivo 6: Assegurar a disponibilidade e gestão sustentável da água e saneamento para todos. Disponível em $<$ https://nacoesunidas.org/pos2015/ods6/> Acesso em 28 dez. 2015.

POMPEU,Tomanik.ÁguasdocesdoBrasil:capitalecológico, usoeconservação.SãoPaulo: Escrituras, 1999.

SILVA, Américo Luís Martins Da. Direito do meio ambiente e dos recursos naturais. São Paulo: Revista dos Tribunais, 2004. v.1.

TUNDISI, José Galizia. Água no século XXI: enfrentando a escassez. São Paulo: RiMa, IIE, 2003.

TUNDISI, José Galizia; TUNDISI, Takako Matsumura. Recursos hídricos no século XXI. São Paulo: Oficina de Textos, 2011. 
UNESCO. Organização das Nações Unidas para a Educação, a Ciência e a Cultura. Gestão maissustentáveldaáguaéurgente,dizrelatóriodaONU.<http://www.unesco.org>Acesso em 26 dez. 2015.

UNILEVER. Água no Brasil. Disponível em: <https://www.portalvital.com/saude/ saude/aagua-no-brasil> Acesso em 27 dez. 2015.

VIEGAS, Eduardo Coral. Visão jurídica da água. Porto Alegre: Livraria do advogado, 2005. 
